\title{
ANOMIA, EXTRAÑAMIENTO Y DESARRAIGO EN LA LITERATURA DEL SIGLO XX: UN ANÁLISIS SOCIOLÓGICO
}

\author{
Irene Martínez Sahuquillo \\ Universidad de Salamanca \\ E-mail: irene@gugu.usal.es
}

\begin{abstract}
RESUMEN
El propósito de este estudio es entender las causas de que fenómenos patológicos como la anomia, el extrañamiento y el desarraigo o "falta de hogar» (homelesness), que han sido abordados por la sociología clásica y moderna, sean también el tema central de muchas obras de la gran literatura del siglo Xx, como Kafka, Sartre, Camus, Roth, T. S. Eliot, Hesse, Lawrence, Musil, etc. Se sostiene que los autores literarios, al escribir sobre esta problemática, no están dando únicamente testimonio de una «enfermedad» ligada genéricamente a la condición del hombre en la sociedad moderna, sino que también están reflejando su propia experiencia vital. Se intenta mostrar que el grupo social de los escritores, en tanto que intelectuales y artistas, está especialmente expuesto al síndrome de anomia, extrañamiento y falta de hogar por causas que tienen que ver no sólo con su situación apátrida y desclasada sino también con su propia tarea de productores de valores cualitativos que chocan con la lógica cuantitativa del mercado. De esta manera se pretende contribuir simultáneamente a una sociología de la obra literaria y del grupo social de los creadores literarios.
\end{abstract}

\section{INTRODUCCIÓN: AFINIDADES ENTRE LA LITERATURA Y LA SOCIOLOGÍA}

Antes de abordar el asunto en el que está centrado este trabajo, no está de más hacer algunas reflexiones sobre las indudables afinidades que existen entre la literatura, y muy particularmente la novela, y la sociología, las cuales pueden

\section{Reis}


ser entendidas como "dos registros diferentes de análisis de la realidad social que pueden llegar a influirse mutuamente», como bien señala José M. González García en su estudio sobre las afinidades electivas entre Max Weber y $\mathrm{Kafka}^{1}$. Incluso aunque no existiera una influencia directa, el literato — al menos el de orientación realista- y el sociólogo están unidos por intereses y propósitos coincidentes, por mucho que les separe la distinta naturaleza de sus respectivas tareas. En efecto, ambos comparten una misma curiosidad por el mundo social que el primero recrea en sus obras y el segundo estudia en sus investigaciones, y también algunas preocupaciones comunes acerca de la realidad social que uno refleja en ficciones y el otro en sus trabajos científicos. Así por ejemplo, la preocupación por la llamada «cuestión social» ha inspirado, desde mediados del siglo XIX, tanto investigaciones sociológicas centradas en la pobreza y otras lacras sociales — como las pioneras de Charles J. Booth y S. Rowntree a finales de siglo-, como novelas que también bucean en las miserias e injusticias provocadas por el avance del capitalismo industrial, desde las célebres novelas de Dickens, hasta las de John Steinbeck y Upton Sinclair, en EE.UU., o las novelas sociales de Baroja, por citar algunos ejemplos representativos de novelistas con inquietudes similares a las que impulsaron la labor de un buen número de sociólogos desde los comienzos de esta disciplina.

Asimismo, si los sociólogos clásicos se impusieron como tarea crucial interpretar las transformaciones que estaban dando paso a un nuevo tipo de sociedad, la sociedad moderna, de forma que quedaran al descubierto no sólo los factores económicos y políticos que contribuyeron a su nacimiento, sino también los factores ideales, de carácter cultural o psicológico, algunos novelistas de la escuela realista — pienso en los exponentes de las denominadas novela social y psicológica- también se propusieron en sus obras explorar los factores espirituales que impulsaron el desarrollo del mundo moderno. Los Buddenbrook, de Thomas Mann, por ejemplo, no es sólo la historia de la decadencia de una familia, sino también la disección del ethos burgués, el mismo que Weber desmenuza en La Ética Protestante, y el análisis de las transformaciones de dicho ethos que desembocan en el declive de los Buddenbrook, claros exponentes de la clase burguesa en sus distintas fases ${ }^{2}$. Incluso en autores que no escriben novelas sociales o psicológicas a la manera realista, como es el caso del novelista y poeta británico D. H. Lawrence, se manifiesta el afán por interpretar — si bien en clave más metafísica que sociológica - las causas espirituales del triunfo del «industrialismo» $y$, curiosamente, se pueden encontrar puntos en común entre su interpretación y la del sociólogo alemán Ferdinand Tönnies, ya que ambos consideran que la raíz de todos los cambios experimentados por la sociedad europea es la aparición de un nuevo tipo de orientación psíquica en el hombre moderno caracterizada por la racionalidad y la voluntad instrumenta-

1 J. M. GonzÁlez García: La máquina burocrática, Madrid, Visor, 1989, p. 23.

2 José María González García ha señalado el paralelismo entre los personajes de la novela y el tipo ideal de burgués protestante que WEBER construyera en La Ética Protestante, en p. 23. 
lizadora de las relaciones humanas. La interpretación y la crítica, en uno y otro autor, están indisolublemente unidas.

De la misma forma, tanto sociólogos como novelistas (sin olvidar a poetas y dramaturgos) se han esforzado no sólo por entender e interpretar las transformaciones que estaban trastocando todo el orden tradicional y generando uno nuevo, con relaciones y tipos sociales distintos, sino también por indagar en las consecuencias psicológicas de la modernización y, así, ahondar en los problemas planteados a la condición humana por el mundo moderno. Así, igual que Georg Simmel se afana por desentrañar los efectos espirituales de la economía monetaria en Filosofía del dinero y de la urbanización en Las grandes urbes y la vida del espiritu, muchos escritores representativos de la literatura moderna han querido mostrar el impacto y las repercusiones que ha tenido el tránsito a la modernidad en la conciencia del hombre y en su vida cotidiana. La figura del flaneur, el urbanita que recorre las calles de la ciudad en actitud observadora y distanciada — un producto típico de la civilización modernaha sido, así, objeto de interés tanto para la sociología como para la literatura desde que Baudelaire lo convirtiera en materia poética. Y el análisis de Simmel de la característica indolencia - la actitud que él llama blasé- del hombre urbano que se protege con esa coraza de indiferencia de un medio ambiente agresivo e impersonal — ha sido llevado a la literatura por clásicos de la novela y el pensamiento como Sartre y Camus, cuyos personajes Antoine Roquentin, de La Náusea, y Mersault, el protagonista de El Extranjero, ejemplifican de forma angustiosa al hombre que se ha distanciado tanto del mundo circundante que es incapaz de establecer conexiones significativas, dotadas, esto es, tanto de sentido como de calidez emocional, con las personas que le rodean.

Otro punto en común entre la sociología (también la presociología) y la literatura de creación es que ambas se han ocupado con especial interés de aquellas patologías que han surgido al hilo del proceso modernizador sufrido por Occidente. Fenómenos como el extrañamiento o la alienación, extensamente tratados por Marx, así como por autores de otras orientaciones teóricas, como la anomia estudiada por Durkheim, o también el desarraigo característico del hombre moderno, el cual ha dejado de sentirse en casa en el mundo que le rodea, como explican Berger, Berger y Kellner en su obra Un mundo sin hogar ${ }^{3}$, han sido abordados por muchos escritores modernos en obras tan conocidas como las dos mencionadas arriba y en otras muchas: en las novelas de Kafka, de Musil, Joseph Roth, Rainer M. Rilke, Hermann Hesse, D. H. Lawrence, Pío Baroja, J. D. Salinger, entre otras muchas, o en poemas emblemáticos del siglo XX, como "La tierra baldía", de T. S. Eliot, o también en el teatro del absurdo. Muchos autores de renombre en la literatura europea y americana han hecho, así, suyas algunas de las preocupaciones por los efectos

${ }^{3}$ P. Berger, B. Berger y H. Kellner: Un mundo sin hogar. Modernización y conciencia, Santander, Sal Terrae, 1979. 
perversos o, al menos, inquietantes de la vida moderna que han orientado las reflexiones e investigaciones de filósofos y sociólogos desde el pasado siglo.

Estas coincidencias no son, en modo alguno, casuales. Si nos centramos en el caso de la novela, el género más característicamente moderno — pues su desarrollo está íntimamente ligado al florecimiento de la burguesía y al progreso de la economía capitalista-, parece claro que, si dejamos al margen las motivaciones de carácter estético que mueven al novelista a escribir, el propósito principal de este género, al menos en su variante realista, es ofrecer un cuadro fidedigno del mundo social en el que están ubicados los distintos escenarios donde van a transcurrir las vidas de los personajes. La dependencia de la biografía de éstos con respecto a las condiciones sociohistóricas que constituyen su marco significativo es un presupuesto que late en La educación sentimental, de Flaubert, como late en otras novelas de relieve de la literatura de los últimos siglos. Y puesto que el marco sociohistórico en el que se sitúan habitualmente las vidas de los protagonistas es el de la sociedad moderna, con sus grandezas y sus miserias, sus conquistas y sus pérdidas, no es de extrañar que la exploración de éstas sea uno de los cometidos del escritor, en su papel de analista y crítico de la sociedad de su época.

El creador literario se convierte, así, en un intérprete, como el sociólogo, de la realidad social y los acontecimientos históricos que la atraviesan aunque, en oposición a éste, no le interesa tanto descubrir tendencias generales como profundizar en los casos particulares en los que una tendencia general se manifiesta; su motivación corre, así, en sentido contrario a la regla durkheimiana que invita a desentenderse de las manifestaciones individuales de un fenómeno social. Con todo, pese a que el escritor se interesa más por las repercusiones individuales de un fenómeno social o psicológico que por éste en abstracto, intenta también, a semejanza del científico social, descubrir las claves que pueden ayudar a interpretarlo. Y ello porque, conviene insistir en este punto, su pretensión no es sólo crear una obra bella: también es la de contribuir con ella a iluminar zonas de la vida social y del alma humana que precisan ser esclarecidas para, de esta manera, hacer una aportación valiosa a la tarea, en la que también han estado empeñados los sociólogos, de aumentar la autoconsciencia de una sociedad cada vez más compleja y más ávida de ideas y conocimientos que puedan servir para comprenderse a sí misma. En este afán de crear una autotransparencia para un mundo problemático los literatos han participado en la misma empresa en la que se han afanado los sociólogos.

En definitiva, la literatura y la sociología han confluido, desde mediados del siglo XIX, en algunos de sus motivos y aspiraciones: tanto una como otra han pretendido ayudar, con sus interpretaciones, a que los hombres se orienten en la civilización moderna, como explica Wolf Lepenies en su estudio Las tres culturas, y, a veces, la empresa literaria ha tenido un carácter marcadamente científico, tal y como ilustran los casos paradigmáticos de Balzac, cuya Comedia humana persigue una comprensión de los hechos de la sociedad análoga a la que Comte aspiraba, y de Flaubert, un escritor que contemplaba la literatura 
como una actividad cuasi científica para la cual era exigible en el autor toda la impassibilité necesaria para investigar la realidad social desde la distancia y la objetividad, un programa que habría hecho las delicias de Durkheim ${ }^{4}$. Para Lepenies, pues, la literatura a veces se ha aproximado a la sociología y ésta a la primera - al menos la sociología de orientación menos naturalista y más hermenéutica-, por lo que cabe entender a la sociología como una «tercera cultura» situada entre la científica y la literaria o humanística. Aunque se suela identificar a la sociología con racionalidad y a la literatura con sentimiento, las cosas no aparecen tan nítidamente diferenciadas en la práctica ${ }^{5}$. Así, por ejemplo, encontramos literatos que, como Flaubert, se comportan como fríos analistas de la sociedad y el individuo, y sociólogos que, como Tönnies, pueden llegar a ofrecer una visión poética de lo que describen, como se hace patente en Comunidad y asociación. Las fronteras entre una y otra actividad existen pero son borrosas y movedizas.

Por todo ello la literatura reviste un doble interés para la sociología. En primer lugar, interesa porque es una actividad social con sus propias leyes de producción y consumo, susceptible de ser estudiada por una sociología específica que dé razón de cosas tales como los condicionantes económicos de dicha actividad, las relaciones entre autores, editores y público, la relación entre la lectura de libros y variables significativas como sexo, edad, nivel educativo o profesión, las funciones sociales del consumo de literatura, etc. En segundo lugar, tiene interés en cuanto que ofrece un cuadro de la realidad social que puede contribuir a nuestro conocimiento de la misma. Comoquiera que, además, lo que suele reflejar el novelista o dramaturgo en sus obras es aquella dimensión interna del mundo que es más inaccesible a la investigación empírica, resulta que la literatura puede llegar a iluminar aspectos de la existencia social a los que la sociología habitualmente no llega. La profundidad del análisis sociológico y psicológico que contiene La Regenta es difícil de encontrar en un estudio sociológico. Aunque la literatura no pueda competir con la ciencia social en exactitud, puede, en cambio, aportar con sus exploraciones de la realidad humana ideas e intuiciones valiosas para un estudioso que quiera penetrar en las zonas más recónditas del mundo social y la psique humana.

Pero además de ser fuente de intuiciones e ideas útiles sobre la realidad social, la literatura tiene interés para el sociólogo en cuanto que expresión de una particular visión del mundo, la propia del escritor, el cual, en sus obras, está reflejando sus valores y esquemas interpretativos. La literatura puede ser, así, contemplada como plasmación que es de la forma de entender y evaluar el mundo de un grupo social específico, el de los intelectuales y artistas - pues algunos escritores se aproximan más al tipo humano de intelectual, como Sartre o Musil, otros al de artista, como Rilke o Hesse-, que, en virtud de sus

${ }^{4}$ W. LEPENIES: Between Literature and Science: the Rise of Sociology, Cambridge, Cambridge Univesity Press, 1988, pp. 1-6 (e.o., Die drei Kulturen, 1985).

5 Como señala Lepenies, ibid., p. 13. 
propios valores, intereses y actitudes ven la realidad desde su peculiar punto de vista. Sus obras son, por tanto, susceptibles de ser estudiadas desde la perspectiva de la sociología del conocimiento, cuya misión es interpretar la cosmovisión o ideología que asoma en ellas a la luz de los factores sociales que están determinando la posición del artista frente al mundo.

Es desde esta perspectiva desde la que pretendo acometer el análisis de la literatura como reflejo de la anomia, extrañamiento y desarraigo del hombre moderno. Por un lado, considero que estos fenómenos han merecido la atención de los literatos por las mismas razones que han suscitado el interés de los filósofos sociales y sociólogos: porque se trata de problemas inherentes a la condición del hombre en la sociedad moderna que cualquier intérprete de ésta debe abordar. Por otro lado, parto del supuesto de que la preocupación de los primeros por esta problemática está ligada al hecho de que su situación específica en la sociedad y la identidad a ella asociada les hace más vulnerables a experiencias que no afectan a todos los colectivos por igual, sino que hacen más fácilmente presa en grupos que, como el de los intelectuales y artistas, está más desvinculado y distanciado del entorno y, por ende, expuesto al «egoísmo» en sentido durkheimiano. Lo que se persigue, en suma, en las páginas que siguen es entender por qué los escritores contemporáneos han hecho de la angustiosa condición anómica, enajenada y desarraigada del hombre moderno el eje de muchas de sus obras y comprender también la postura que han adoptado frente a ella, así como la cosmovisión en la que esta postura está integrada.

\section{LA LITERATURA MODERNA COMO TESTIMONIO DE LA ANOMIA, EXTRAÑAMIENTO Y DESARRAIGO Y COMO FILOSOFÍA GLORIFICADORA DEL OUTSIDER}

$\mathrm{Al}$ asomarse a las grandes obras de la literatura del siglo $\mathrm{XX}$, un hecho se pone de manifiesto: muchas de ellas giran en torno a la problemática definida por Ernst Fischer como "la soledad del hombre en medio de un mundo que se ha hecho extraño» ${ }^{6}$. Multitud de novelas, a las que hay que añadir algunas obras poéticas y dramáticas, intentan plasmar la experiencia de un hombre, el hombre moderno, que se ha alienado de su entorno social. La condición de éste puede ser descrita con las siguientes palabras de Robert Musil: «En el centro, el individuo. Su desamparo. Los hechos, en monstruoso crecimiento. El abismo, infranqueable, entre el individuo y la colectividad ${ }^{7}$. Esta vivencia de soledad y enajenación respecto a los otros está estrechamente unida a otras dos experiencias. En primer lugar, la desorientación que se deriva de lo que Durk-

6 Lo dice Ernst Fischer, a propósito de Robert Musil, en E. FISCHER: Literatura y crisis de la civilización europea: Kraus, Musil, Kafka, Barcelona, Icaria, 1984, p. 61.

7 Ibid. 
heim llamó anomia y que puede entenderse, de acuerdo con la propuesta de Peter Berger, como ausencia de orden significativo o de "nomos» en la conciencia del individuo ${ }^{8}$. En la medida que ese vacío nómico se produce porque aquél se ha desgajado de la sociedad y ésta ha dejado de servirle de fuente de creencias, valores y normas con las que construir un orden moral y cognitivo, se puede decir que la anomia es una consecuencia del extrañamiento. En segundo lugar, otra experiencia, igualmente ligada a las anteriores, es el desarraigo, lo que los sociólogos P. Berger, B. Berger y H. Kellner llaman homelessness, esto es, falta de hogar, y que se refiere al hecho de que los hombres se han dejado de sentir en casa en la sociedad, percibida como incomprensible, lejana, impersonal, inhumana. Como es claramente visible, el desarraigo y el extrañamiento son caras de la misma moneda.

Tan estrechamente entrelazados están estos tres fenómenos, que los escritores no distinguen entre ellos y hacen padecer a sus personajes las tres dolencias anímicas a un mismo tiempo. Así, por ejemplo, Franz Tunda, el protagonista de la novela Fuga sin fin, de Joseph Roth, es el prototipo de hombre que vive sin norte, que viaja de unos países a otros y no echa raíces en ninguno, ni tampoco ninguna mujer es capaz de retenerle, que se siente un extraño entre los demás hombres y que tampoco es capaz de dotarse de unos valores y creencias sólidos en los que fundamentar su vida. De él dice el autor que "no se sentía en casa en este mundo». Es un claro exponente de desarraigo, anomia y extrañamiento, que no son sino manifestaciones de un mismo síndrome: la falta de integración del hombre en el cuerpo social, fenómeno al que Durkheim dio el nombre de egoísmo.

En efecto, ese proceso impulsado por la modernización consistente en que el individuo se va separando cada vez más de la colectividad, se va distanciando, también, de los productos de la actividad humana — que se le aparecen como un "poder social extraño", en palabras de Marx-y, como consecuencia, va replegándose en su yo, se toma como «su propio y único objeto" y la da por observarse y analizarse, Durkheim dixit ${ }^{9}$, es el que los sociólogos han intentado explicar e interpretar y los literatos han recreado, explorado y analizado. Los segundos, además, han procurado transmitir en sus obras todos los sentimientos y estados anímicos que van unidos a dicho síndrome y que, a veces, dan título a la novela. Me refiero a sentimientos tales como el de soledad, angustia, espanto, «la náusea» (Sartre), el «desasosiego» (Pessoa), la indolencia, «el aburrimiento» (Moravia), la desorientación, la confusión, la falta de sentido y un largo etcétera. Es por ello por lo que la novela de siglo XX resulta ser un arte tenso y desgarrado: porque refleja la crisis espiritual del hombre en el mundo moderno, porque es una novela de crisis, como la definió Ernesto Sábato, que, como tal, reproduce y amplifica los males que sufren los habitantes de la sociedad moderna.

${ }^{8}$ Esta intepretación puede verse, entre otras obras, en P. BERGER: El dosel sagrado, Buenos Aires, Amorrortu, 1971.

9 E. Durkheim: El suicidio, Madrid, Akal, 1976, p. 304. 
Así pues, los escritores europeos y americanos de distintas procedencias y generaciones han creado personajes, como el arriba mencionado, que personifican diversas maneras de vivir un mismo síndrome que se puede desdoblar en tres fenómenos: la pérdida de realidad, la pérdida de sentido y la pérdida de hogar. La pérdida de realidad se convirtió en un tema central de la literatura desde el Romanticismo, como acertadamente señala Ernst Fischer ${ }^{10}$. Se podrían citar un sinnúmero de obras en las que los héroes o antihéroes problemáticos experimentan la sensación de irrealidad con respecto a las cosas y personas que les rodean. A veces esa acusación de «irreal» es lanzada por el autor contra toda la civilización. Este es el caso del poeta T. S. Eliot, quien en su poema " $L a$ tierra baldia» condensa su sentimiento de alienidad e irrealidad que le provoca la sociedad moderna en la sentencia "ciudad irreal», sociedad que tampoco merece elogios en otro poema titulado Los hombres huecos, en el que ésta aparece como la "tierra muerta, tierra cactácea» habitada por hombres vacíos por dentro. El artista expresa, así, su enajenación del mundo negándole realidad, desrealizándolo, por lo que éste cobra, con frecuencia, un aire fantasmal.

Este impulso desrealizador, que caracteriza a algunas corrientes artísticas, como el expresionismo ${ }^{11}$, está presente en las obras de D. H. Lawrence, las cuales giran alrededor de una misma problemática: el extrañamiento de sus héroes y heroínas del entorno industrial y la búsqueda de realidad y sentido en la esfera privada de las relaciones de carácter pasional que se establecen entre los renegados de la civilización. De acuerdo con el ideario romántico antimoderno del escritor, dado que el ámbito social se ha vuelto «irreal», ajeno, insignificante para el individuo, éste debe apartarse de él voluntariamente y lanzarse a una vida intensa, próxima a la naturaleza (pues si en Lawrence la sociedad no es fuente de «nomos» sí lo es, profundamente, la naturaleza) desde la que construir el sentido de la existencia. Es la salida que eligen también Rainer Maria Rilke, otro vitalista romántico que contrapone vida a sociedad, y Hermann Hesse. Ambos autores proponen una suerte de religión del yo, con su correspondiente culto a la intimidad, en especial, los sentimientos, con la consecuencia de hacer de su típicamente romántica Weltfremdheit (ajenidad respecto a mundo) una vía para acceder a una vida más noble y elevada.

Otros autores de la literatura moderna, en cambio, no han pretendido sublimar la experiencia de alienación ni ofrecer una cosmovisión restauradora del sentido perdido, sino que han sondeado en el alma del enajenado y han desplegado ante nuestros ojos los efectos devastadores de la experiencia de pérdida de realidad y significación de las cosas. Así, Sartre se recrea en las vivencias anímicas y anómicas de Antoine Roquentin, protagonista de la ya citada novela La náusea, que encarna al hombre vacío, sin rumbo, solo y enajenado,

10 E. FISCHER: El artista y su época, Madrid, Fundamentos, 1972, p. 18.

11 Como explica Ferdinand Fellmann, los expresionistas han hecho eje de su arte su experiencia de la irrealidad del mundo y su voluntad de disolver la realidad, F. Fellmann: Fenomenología y expresionismo, Barcelona, Alfa, 1984, p. 35. 
tanto que a veces hasta su propio yo pierde contenido, de tal forma que se llega a no reconocer cuando se mira el espejo, ni a sentirse, pues se ha convertido en un extraño para sí mismo. La autoalienación puede ser considerada como la forma más extrema de alienación. Por su lado, su compatriota Camus también aborda la completa pérdida de relación con la realidad de un personaje a la deriva, Meursault, «el extranjero», quien es incapaz — tal es la ajenidad que siente hacia todo- de entristecerse por la muerte de su madre, de querer a su amante ni de evitar que el calor se adueñe de su voluntad de tal forma que desencadene un absurdo crimen. La falta de significación de todo cuanto le rodea —y de sí mismo - le ha conducido a la indiferencia más absoluta y convertido en un asesino sin móvil. Una indiferencia que también es la nota dominante de El aburrimiento, de Alberto Moravia, cuyo personaje central padece de un aburrimiento extremo que nace del "absurdo de una realidad que, como ya he dicho, es insuficiente, es decir, incapaz de persuadirme de su propia existencia». En un comentario a su obra, Moravia explica que está hablando de "la incapacidad del sujeto de restablecer la perdida relación con los objetos del mundo que le rodea», un mal que proviene, dice, de la alienación ${ }^{12}$.

Otras novelas donde se tratan temáticas similares son El hombre perdido, de Ramón Gómez de la Serna; El hombre sin atributos, de Robert Musil, y El guardián entre el centeno, del escritor norteamericano J.D. Salinger, por citar sólo algunos títulos significativos. El hombre perdido es un retrato de un hombre anónimo — ni siquiera tiene nombre — que está embarcado en un peregrinaje errático en busca de algún sentido para la vida, una vida de la que está "desasido" y en la que no es capaz de orientarse. El final no puede ser más trágico: muere arrollado por un tren de mercancías, tal vez de forma voluntaria. Como a Andrés Hurtado, el protagonista de El árbol de la vida, de Baroja, la falta de sentido y el desarraigo le ha conducido a desprenderse de la vida.

El hombre sin atributos plantea, por su lado, el drama del hombre desgajado de su entorno social y en contradicción con todo. Ulrich, el protagonista, es otro héroe problemático que se siente alienado de la decadente sociedad austriaca que le rodea y elige vivir una vida al margen de todo convencionalismo, incluso hasta el extremo de mantener relaciones incestuosas con su hermana. Es uno de esos personajes que se refugian en la esfera privada y se recrean en las emociones que proporcionan las relaciones más íntimas como vía para escapar a la vivencia de falta de sentido. Pero Musil, a diferencia de los escritores románticos, no convierte esa huida en un programa ideológico sino que, por el contrario, se esfuerza por mostrar lo imposible que es escapar de la sociedad y lo poco deseable que es buscar una salvación individual.

Otra novela que recrea las tribulaciones de un personaje perdido es la citada obra de Salinger, El guardián entre el centeno, un gran éxito de ventas desde que se publicara en los años cuarenta. En este caso el anómico es un adolescen-

12 E. FisCHER, El artista y su época, ref. cit., p. 143. 
te, Holden Caulfield, incapaz de adaptarse a una sociedad y una forma de vida, la americana, que sólo le produce asco y un inconformismo sin causa que le conduce al aislamiento. Los allegados le achacan que no sabe lo que quiere, que carece de dirección, y, efectivamente, lo único que Holden tiene claro es que detesta el mundo que le rodea porque todo en él es falso, hipócrita, deprimente. Tal es su desorientación vital que cuando su hermana le pregunta sobre lo que querría ser, todo lo que se le ocurre es el oficio de guardián entre el centeno, un guardián cuyo cometido fuese impedir que los niños que jugaran en ese campo de centeno se cayesen por el precipicio. Una idea infantil que ilustra la falta de sentido de realidad que padece el muchacho y su incapacidad para identificarse con el mundo adulto.

Pero no se puede disertar sobre la alienación en la literatura moderna sin hacer referencia al autor que mejor ha sabido transmitir el horror de la enajenación del hombre en un mundo burocrático impenetrable y absurdo y dotado de un poder omnímodo sobre el individuo, tanto que llega a introyectarse en su psique y a producirle culpabilidad: estoy hablando, naturalmente, de Franz Kafka. La tragedia que plantea el genial judío checo, desde su experiencia de desarraigo, de no pertenecer a ninguna comunidad — hasta en su propio medio familiar se sentía un extraño-, es la tragedia de una realidad que se ha vuelto tan extraña que ha perdido todo su sentido. En esa realidad fantasmagórica - formada por estructuras burocráticas y relaciones cosificadas- ni siquiera el individuo puede encontrarse a sí mismo; es a lo que remite el recurso kafkiano de ir suprimiendo nombres (el personaje de El proceso, Joseph K., ha perdido su apellido; el protagonista de El castillo, K., es sólo una inicial). Su filosofía no puede ser más pesimista pues, a sus ojos, la «jaula de hierro» aprisiona con tal fuerza al individuo que éste no puede hacer nada, está condenado a la pasividad. Kafka traduce, así, como indica Ernst Fischer, la sensación de impotencia e indefensión del hombre en un mundo en el que el individuo aparentemente no puede influir lo más mínimo ${ }^{13}$. El extrañamiento desemboca, en las novelas de Kafka, en sumisión y autodestrucción.

Con este pequeño recorrido por la literatura del siglo XX se trataba de mostrar, a través de algunos casos significativos, cómo los grandes escritores del siglo XX, a semejanza de algunos filósofos sociales y sociólogos, han considerado que el extrañamiento, la anomia y el desarraigo o falta de hogar son males constitutivos de la sociedad moderna y han partido del supuesto de que esa vivencia es universalmente sentida por los hombres y mujeres de este siglo y no necesariamente en exclusiva por individuos de las características de los creadores literarios, esto es, personas propensas a distanciarse de la realidad y a entregarse al autoanálisis en virtud de su vocación intelectual y artística. Los escritores han pretendido, así pues, no sólo verter en sus obras sus propias experiencias y sufrimientos, sino también dar voz a vivencias colectivas para,

13 Como plantea FISCHER en su obra Literatura y crisis de la civilización europea, ref. cit., p. 148. 
de este modo, ofrecer un espejo en el que también el lector común se puede reconocer.

Ello no obstante, los escritores no se han limitado a ofrecer un cuadro neutro del síndrome considerado: además, y fundamentalmente, han expresado su propia interpretación del fenómeno $\mathrm{y}$, a veces, han ofrecido una cosmovisión en la que esa experiencia cobra sentido y se ve legitimada. Por supuesto, las posturas de unos y de otros no son coincidentes. En lo único en lo que son unánimes los distintos escritores citados es en el juicio absolutorio que les merecen los distintos personajes enajenados y descarriados que dibujan en sus obras. Incluso el asesino Meursault es retratado con simpatía —o al menos comprensión- por Camus que lo presenta como una víctima de las circunstancias. Todos parecen dar por sentado que si hay algún culpable de la aparición de ese supuesto mal, ese culpable es la sociedad: la burocracia en Kafka, la sociedad burguesa en Hesse, el mundo industrial en Lawrence, la sociedad americana en Salinger, y así sucesivamente. Siempre es el individuo la víctima de un sistema inhumano que le cosifica o de un medio hostil que es incapaz de acomodar su alma, de encauzar sus energías y su ansia de sentido. En ocasiones, el personaje que encarna la anomia y el extrañamiento es víctima de una enfermedad que puede denominarse «intelectualismo» — muy ligada a lo que Durkheim definió como egoísmo- y que consiste en que el sujeto se ha distanciado tanto de la realidad -incluidos sus semejantes- a fuerza de convertirla en objeto de su actividad mental, que ya no es capaz de tender puentes que le permitan retornar a ella y sentirla como propia: la ve como algo radicalmente ajeno, cósico, desprovisto de sentido. Es la enfermedad del intelectual y no es de extrañar que sean escritores con los rasgos típicos del intelectual abstractivo - como Sartre o Musil- los que la convierten en materia literaria proyectando, así, sus propios fantasmas en obras que tienen mucho de autoanálisis.

Pero la postura que adoptan ante la problemática difiere según sean los estilos cognitivos de cada autor y el modelo de artista o escritor con el que se identifican. Así, por ejemplo, hay escritores que ven el fenómeno como una tragedia que debe ser denunciada y condenada y que presentan al hombre alienado como un mártir que está sufriendo las consecuencias de la deshumanización del mundo social o de la degradación de las relaciones sociales: es el caso de Kafka, el más trágico y desesperanzado crítico de las estructuras alienantes de la sociedad moderna. En otro estilo, más cercano a la crítica y la denuncia social que a la tragedia, también puede incluirse en esta categoría a Salinger o Camus quienes, al igual que otros muchos autores sobre los que no he tratado, probablemente se identificaran con la figura del escritor como conciencia moral de la sociedad. Otra forma de plantear los términos es la representada por aquellos escritores que pertenecen a la categoría del intelectual puro y que se identifican con la tarea de ser la conciencia representativa o teorética de la sociedad, para lo cual procuran que sus obras sirvan de espejo en el que la sociedad pueda mirarse. Estos autores también pueden adoptar una postura 
reprobatoria frente al fenómeno — como sucede con Moravia, Pessoa o Musil_, si bien lo que me interesa destacar de ellos es que tienden a considerar que la alienación anómica y el desarraigo forman parte del destino de algunos hombres especialmente proclives, por su función o por sus características personales, a mantener una actitud distanciada, desvinculada y afectivamene neutra frente a la realidad. Así, Robert Musil defendía explícitamente la necesidad de "hombres sin vinculaciones», investigadores puros y experimentados que tengan "la virtud de la duda atrevida». Su propuesta en El hombre sin atributos de crear un "secretariado mundial de la exactitud del alma» revela su afinidad con la figura del científico ${ }^{14}$. En definitiva, lo que Musil plantea es hacer de la necesidad virtud y convertir el distanciamiento extrañado del mundo, consustancial a la tarea del intelectual, en una actitud legítima y fructífera. En él, como en otros autores de la misma orientación, hay una cierta aceptación de la alienación, la anomia y el desarraigo como destino ineludible del intelectual, aunque ello no signifique que no sean conscientes de las patologías que esa desvinculación extrema puede generar.

El último planteamiento que cabe distinguir es el que se encuentra en las obras de los escritores de orientación neorromántica que se identifican con la figura del artista puro - del Dichter sacro y no del Schrifsteller profano- y que hacen de su arte una religión. Autores como Lawrence, Hesse y Rilke consideran que la soledad y el sufrimiento son el destino del artista y, en este caso, no como consecuencia perversa del extrañamiento, sino como señal de pertenecer a una clase de hombres superiores que saben que, como decía Novalis, "todo dolor es recuerdo de nuestra alta condición». El desarraigo y la enajenación con respecto a un entorno "desrealizado" son convertidos así en un sistema de vida por el artista romántico que se sabe un ser aparte y que hace de ese apartamiento un signo de distinción. La figura del "aussenseiter» en Hesse es, de esta manera, glorificada, pues se considera que el hombre de sensibilidad elevada no puede por menos que vivir al margen de una sociedad que se ha apartado de la vida y se ha alejado de las auténticas necesidades humanas. $\mathrm{Y}$, además, el impulso más fuerte del alma romántica es escapar de la anomia construyendo una "cosmovisión" que dote de sentido al mundo y a la existencia, para lo cual, y dado que el sentido no se encuentra en la secularizada y materialista sociedad circundante, el individuo tiene que ensimismarse, buscarse a sí mismo o, incluso, perderse a sí mismo, ya que una de las cosas que persigue el artista romántico es, en palabras de Hesse, deshacerse de la «culpa de la individuación» y alcanzar la unio mystica con el todo. En suma, el artista romántico acepta la enajenación respecto de la sociedad no ya sólo como un prosaico destino inevitable —al modo del escritor «intelectualista»- sino como una señal de pertenencia a los elegidos en vez de al rebaño de los hombres vulgares; su lucha contra la anomia y la falta de hogar se traduce en el cultivo de una religión del yo y de la vida que pueda proporcionar sentido y

14 Para un buen análisis de la obra de Musil, véase ibid., pp. 39-101. 
patria espiritual. De esta manera, adoptando una cosmovisión nomificadora escapan a los efectos del egoísmo y se «religan» no ya a la sociedad pero sí a la vida y la naturaleza, así como a una comunidad de aristócratas espirituales.

\section{ELEMENTOS PARA UNA INTERPRETACION DE LA LITERATURA DEL EXTRAÑAMIENTO}

Para comprender por qué la literatura del siglo Xx ha hecho del extrañamiento del hombre, su desarraigo y su propensión anómica un tema central e insistente es necesario tener en cuenta las dos dimensiones que, como antes se ha apuntado, posee una obra literaria: la dimensión objetiva como espejo en el que se refleja el hombre y la sociedad de una época y la dimensión subjetiva, que hace referencia a la función expresiva de los propios sentimientos, ideas, obsesiones, conflictos y, en general, de la propia Weltanschauung del artista que se proyecta en la obra. En lo que atañe a la primera dimensión o función habría que determinar en qué medida los escritores están describiendo males que están extendidos en la sociedad moderna y que forman parte del destino del hombre moderno, mientras que en lo que atañe a la segunda habría que dilucidar en qué medida están vertiendo en sus obras sus propias vivencias y su particular visión de un problema que les afecta especialmente en virtud de sus peculiares características como grupo específico que sufre más intensamente que otros los fenómenos considerados.

A mi entender, no se puede plantear correctamente la cuestión si se olvida alguna de estas dimensiones. Parece evidente que los escritores son hijos de su tiempo, que comparten con sus contemporáneos experiencias y representaciones semejantes y que, al reflejar éstas en sus obras, están construyendo un cuadro con el que aquéllos se pueden identificar. Pero también es cierto que en ese cuadro no sólo están intentando dar forma a un sentir general, sino también expresar su propio sentir. Hasta un escritor tan formalmente objetivo como Flaubert reconoció sin ambages que «Madame Bovary soy yo». Por tanto, y como ya he indicado, es necesario enfocar el asunto que nos ocupa desde la perspectiva de la sociología del conocimiento que tenga en cuenta los factores sociales que determinan la conciencia de ese grupo específico formado por los artistas y los intelectuales.

\subsection{La literatura del extrañamiento como expresión de la condición del hombre en el mundo moderno}

La literatura moderna —es la primera hipótesis que quiero defender-al explorar ese cuadro psicosocial que sufren los protagonistas de algunas obras capitales y que filósofos y sociólogos han denominado alienación, anomia y falta de hogar, están dando testimonio de un fenómeno que aparece y se desarrolla en las sociedades industriales y que está ligado a las condiciones estructu- 
rales de la vida moderna. Como dicho fenómeno se suele desdoblar en tres problemáticas distintas, me voy a referir a cada una de ellas por separado.

En primer lugar, nos encontraríamos con el problema que expresa brillantemente Anton C. Zijderveld en su obra La sociedad abstracta ${ }^{15}$, consistente en que, como consecuencia del proceso de racionalización y burocratización analizado por Weber, la sociedad se ha ido tornando progresivamente abstracta, alejada de la experiencia ordinaria de los individuos que la perciben como algo extraño, ajeno, no significativo para sus vidas. De ahí que el concepto clave para definir las relaciones entre individuo y sociedad moderna sea el de "alienación", pues aquél se ve incapaz de comprender y de controlar las estructuras abstractas que lo rodean y, por ello, se siente impotente y desvalido. Comoquiera que las instituciones sociales y los roles a ellas ligados han perdido la capacidad de dirigir al hombre interiormente, pues han perdido su significación subjetiva, el individuo se encuentra, por primera vez en la historia, solo ante sí mismo. Emil Oesterreicher ha abundado en esta idea, manteniendo que la condición del hombre en la sociedad moderna es estar condenado a distanciarse de la realidad que lo envuelve y de sí mismo y a experimentar su vida como autocreación ${ }^{16}$. Ambos consideran que la privatización de la identidad es una característica de la vida moderna, pues el individuo se ve progresivamente arrojado a los vacíos que deja el mundo institucional - la vida privada- donde tiene que construir la experiencia de sentido y de realidad, convertida en algo puramente personal. Un producto típico de este fenómeno sería, como señala Zijderveld, "el hombre emocional», que es aquel que vive encerrado en su propia subjetividad y es incapaz de establecer lazos de ningún tipo con el mundo externo objetivo. Precisamente esa "patología» es la que algunos de los autores que hemos tratado, especialmente los que pertenecen a la categoría del «artista romántico», intentan convertir en una filosofía y un modo de existencia debidamente legitimado. Otros, en cambio, aprovechan esa alienación subjetiva para distanciarse intelectualmente del mundo, e incluso de sí mismos, y analizar las cosas con una objetividad y crudeza implacables, convertidos en diseccionadores del alma humana y de la vida social. Todos ellos van a interpretar la alienación en su identidad, unos convirtiendo ese elemento en una ventaja que permite acceder a una vida más alta, lejos del mundanal ruido de la sociedad; otros, aceptándolo como su sino, y algunos, como Kafka, viviéndolo como una tragedia.

En segundo lugar, hay que hacer referencia a la anomia, un fenómeno que Durkheim consideraba un peligro permanente en las sociedades modernas como consecuencia de la atomización y de la pérdida de unidad moral. Como plantean diversos autores — Berger, Berger y Kellner o Luckmann ${ }^{17}$ —, la seg-

15 A. C. Zijverdeld: The Abstract Society. A Cultural Analysis of our Time, Harmondsworth, Penguin, 1972 .

16 E. Oesterreicher: "The Privatization of the Self in Modern Society», Social Research, 1979, 46, 3, pp. 601-615.

${ }_{17}$ Me refiero a diversas obras de estos autores como las ya citadas El dosel sagrado y Un mundo sin hogar, y a Th. LuCKMAnN: La religión invisible, Salamanca, Sígueme, 1973. 
mentación, especialización y racionalización de las instituciones sufridas en ellas, en suma, la fragmentación social, conducen a una erosión de los universos simbólicos comunes y, de esta manera, crean condiciones propicias para que aparezca la anomia. Mientras que en la sociedad tradicional la identidad del individuo se sustentaba sobre un nomos integrador de carácter religioso que estructuraba su vida y daba sentido a su experiencia, en la sociedad moderna, fragmentada y pluralista, no hay tal marco común de significado y la identidad se complejiza: se hace más abierta, reflexiva, segmentada e individualiza$\mathrm{da}$, lo cual puede llevar a que el individuo tenga dificultades para construir una identidad unitaria. De ahí nace el sentimiento de extrañamiento respecto de sí mismo, que algunos de los novelistas tratados han sabido recrear tan magistralmente en sus obras. La especial exposición a la anomia del hombre moderno, pues, es una condición estructural de las sociedades actuales, por definición abiertas, fragmentadas y plurales y que, dadas estas características, favorecen que el individuo se sienta perdido, en busca permanente de sí mismo. Los escritores han intentado, así, reflejar una malaise colectiva y algunos incluso han ofrecido un remedio contra ese mal: una cosmología y un programa de vida «nomificador».

En tercer lugar, e íntimamente ligado a lo anterior, el otro peligro que acecha al hombre moderno es el del desarraigo y la falta de hogar. Dado que la sociedad se ha vuelto progresivamente abstracta y ajena y que además se presenta dividida en multitud de "mundos-de-vida» compartimentados — que obligan al individuo que transita por ellos a cambiar de rol como se cambia de chaqueta - cuyo pluralismo social y simbólico conduce a una pérdida de plausibilidad de las definiciones religiosas y cuya movilidad horizontal y vertical complejiza en grado sumo la formación de una identidad sólida y permanente, se produce el fenómeno anteriormente aludido de la homelesness que se traduce en la experiencia del individuo de no sentirse en casa en el mundo social, percibido como inhóspito e incapaz de cobijarle. Éste se siente, así, desarraigado y desplazado — según Luhmann su situación es estar a priori socialmente desplazado-, ya que, aunque pertenece a varios subsistemas de la sociedad, ninguno de ellos cuenta con su plena lealtad y adhesión, en ninguno de ellos se siente como en casa, siempre es, dice Luhmann, un extraño parcial que no llega a ser completamente nativo en ninguno ${ }^{18}$. Por supuesto, esta situación estructural puede desembocar también en falta de sentido, que es, en definitiva, el peligro mayor al que se enfrenta el hombre, el hombre de todas las épocas, pues forma parte de la condición humana estar expuesto a esa experiencia, y, en particular, el hombre de la época contemporánea. Es esa vivencia de desamparo, de falta de norte y de raíces, de pérdida de sentido, la que han intentado capturar los escritores modernos en sus obras con tal fortuna que muchos lectores se han sentido identificados con los protagonistas.

18 N. Luhmann: Love as Passion: the Codification of Intimacy, Cambridge, Mass., Harvard University Press, 1986, pp. 15 y 95. 
En suma, la literatura moderna del extrañamiento, anomia y desarraigo surge como consecuencia de la extensión de estos fenómenos en el mundo moderno, fenómenos que afectan tan profundamente a la vida e identidad de los individuos que los escritores los han convertido en temas primordiales de sus obras. A su vez, en cuanto que hombres de su época que participan de similares experiencias socialmente condicionadas, los novelistas han proyectado en sus obras sus propias vivencias y tribulaciones. Sin embargo, la explicación no termina ahí: la cuestión es mucho más compleja, pues no se puede partir de la suposición de que las experiencias de los individuos que habitan en una sociedad son homogéneas. Por el contrario, la variedad de experiencias vitales es enorme, dependiendo de la ubicación de cada individuo en la esfera social, que puede determinar cosas como su forma de vida y de pensamiento.

La tesis que he adelantado ya y que me propongo exponer a continuación es que los fenómenos abordados en la literatura de creación - y tratados también en la literatura sociológica - no afectan a todos los individuos por igual, sino que afectan especialmente a ciertos grupos cuyas características sociales, psicológicas e intelectuales les hacen más vulnerables al síndrome analizado: son más vulnerables los habitantes de las grandes ciudades y de las profesiones liberales, que — como estudió Durkheim en El suicidio- están más expuestos al "egoísmo»; también son más vulnerables los jóvenes que los adultos, especialmente los estudiantes, por ocupar una posición periférica en la vida social, alejada de la esfera productiva a la vez que subinstitucionalizada, y, asimismo, por encontrarse en una etapa de formación de la identidad en la que se hacen más acuciantes las preguntas sobre el sentido de la existencia; por último, y es en lo que voy a centrar mi exposición, los intelectuales y los artistas forman un colectivo particularmente expuesto a las experiencias que configuran el síndrome, no sólo por pertenecer a una profesión intelectual liberal, sino también por otras razones que voy a delinear más adelante.

\subsection{La literatura del extrañamiento como reflejo de la experiencia del mundo moderno de los intelectuales y los artistas}

La anomia, el extrañamiento y el desarraigo no son fenómenos que se puedan atribuir, abstracta y generalizadamente, al "hombre moderno" como si hubiera una comunidad plenaria de experiencia que hace que todos los individuos en la época moderna vivan el mundo de la misma manera, sino que, más bien, se han planteado como hechos genéricos porque los intérpretes, tanto literatos como sociólogos, han tendido a partir de sus propias experiencias personales al analizar la condición del hombre moderno y han construido un modelo de hombre altamente problemático en el que han proyectado su propia forma de experimentar la existencia. Las objeciones que se pueden hacer, efec- 
tivamente, a los sociólogos que antes he citado es que extrapolan experiencias de algunos grupos a toda la población y que tienden a exagerar el grado en que ciertos procesos - que sin duda recorren la sociedad moderna- han calado en la conciencia de los individuos.

Así, la secularización no ha avanzado tanto como para producir una crisis de sentido en la mayoría de los habitantes del mundo moderno, ni los valores y formas de vida característicos de la sociedad preindustrial han desaparecido del todo: existen, por el contrario, multitud de nichos de seguridad que resguardan al individuo de las incertidumbres e inclemencias del entorno y en los que el sujeto puede sentirse en casa. Además es dudosa la suposición de que cualquier hombre tiene necesidad de dotarse de un nomos integrador de manera que, cuando la sociedad no se lo proporciona, se ve abocado a la desorientación vital y la crisis: muchas personas pueden vivir huérfanas de un universo simbólico unitario sin caer en la anomia, de la misma manera que pueden carecer de una identidad integradora sin experimentar crisis alguna. Son los individuos que, por sus inclinaciones personales y función social, tienen tendencia a plantearse problemas existenciales y a cuestionar el mundo que les rodea y su propio lugar en él, los que pueden más fácilmente caer presa de las patologías objeto de análisis.

Así pues, los intelectuales y los artistas forman un grupo social especialmente expuesto a las experiencias del extrañamiento, del desarraigo y la anomia y ello por, entre otras, las causas que siguen. En primer lugar, se trata del grupo que, en virtud de su profesión, está más alejado, como ha indicado Michael Löwy ${ }^{19}$, del proceso de producción material, ya que está integrado por personas que producen bienes inmateriales, como el arte y el pensamiento, y que, por tanto, disfrutan de una posición relativamente desligada - Mannheim los calificó, siguiendo a Alfred Weber, de freishwebend, esto es, «libremente flotantes» - en relación con otros grupos más vinculados a una clase social determinada. Su autonomía relativa y su desvinculación de otros grupos, incluso de la pequeña burguesía de la que muchos proceden - de la que le separan desde circunstancias materiales hasta factores inmateriales como valores y forma de vida - hace que, como señala Mannheim en «Ideología y utopía, carezcan de hogar dentro de la sociedad ${ }^{20}$. Esa condición apátrida, por un lado, genera mayor libertad pero, por otro, puede favorecer la sensación de desarraigo, de no pertenecer a ninguna comunidad, de ser un extraño, un extranjero perpetuo en el mundo social.

Por supuesto hay otros factores que pueden colaborar a la aparición de este sentimiento, como es la pertenencia a una minoría que, como la judía, ha tenido siempre dificultades para ser aceptada y para integrarse. Casos como el de Franz Kafka y Joseph Roth, judíos germanoparlantes de zonas no alemanas del

19 Vid. M. LÖWY: Para una sociología de los intelectuales revolucionarios: la evolución politica de Lukács 1909-1929, Madrid, Siglo XXI, 1978, pp. 17-18.

${ }^{20}$ K. Mannheim, Ideología y utopía, México, Fondo de Cultura Económica, 1987, p. 141. 
Imperio austro-húngaro, ejemplifican el prototipo del "extraño universal», en palabras de Zygmunt Bauman ${ }^{21}$, que no puede echar raíces en ningún lugar, que está condenado sin remisión al exilio espiritual. Otras veces, no es por pertenecer a una minoría cultural, sino por haber abandonado un medio social, el de la familia de origen, y no haberse integrado en ningún otro lo que favorece el desarraigo y el extrañamiento. Este es el caso de D. H. Lawrence, quien procedía de la clase obrera — su padre era minero- y quien no llegó nunca a sentirse en casa en su clase de destino, la clase media ni en los círculos aristocráticos que frecuentaba una vez consagrado como escritor. Su condición de desclasado era, para él, una fuente de padecimientos y desorientación y siempre sintió nostalgia de la "solidaridad» en sentido durkheimiano que reinaba en la comunidad minera de su infancia. El desarraigo, la amenaza de anomia y el extrañamiento le acompañaron toda su vida de escritor. La movilidad, así pues, en Lawrence como en Camus — quien era, también, de humilde extracción-, sin duda contribuyeron a crear una conciencia de ser aparte, de extraño, favorecedora de las experiencias consideradas.

Hay que tener en cuenta, asimismo, que los intelectuales y artistas forman un grupo especialmente móvil geográficamente, lo cual acrecienta su carácter apátrida y la naturaleza nomádica, fronteriza y pluralista de su identidad. No es extraño que puedan crear con tanta verosimilitud personajes de vida inquieta, inestable, en permanente peregrinaje físico o espiritual, ya que esa ha sido, en muchos casos, la historia de su vida. No hay que olvidar, en todo caso, que muchos de los autores aquí considerados vieron una época de guerras, de cambios de fronteras y de grandes transformaciones, que impuso a muchos la necesidad de emigrar e, incluso, de exiliarse por motivos políticos. Además la profesión de escritor estaba poco institucionalizada y la vida de éste era, por necesidad, libre y sin ataduras a la par que inestable. Hay quien sostiene, desde luego, que en la actualidad los intelectuales han experimentado una suerte de "revolución neolítica» y han pasado de una vida nómada a una vida establecida con una tierra que sembrar: las universidades y las burocracias. Para Zygmunt Bauman, el autor al que me refiero, el intelectual de Mannheim libremente flotante es ahora una excepción y el desarraigo y la alienación han dejado de ser notas dominantes de su identidad ${ }^{22}$. Por supuesto, Bauman está pensando no precisamente en los escritores, sino más bien en todos aquellos profesores, técnicos y científicos que integran la "clase del conocimiento». Su tesis no es del todo aplicable al grupo reducido y no enteramente establecido de los creadores literarios.

Pero además de la mayor dificultad para integrarse, dada su posición excéntrica con respecto a las clases sociales y el carácter social y geográficamente móvil de su existencia, hay otro factor de índole espiritual que hace que los intelectuales y los artistas se sientan alienados del mundo social o, al menos, lo

${ }^{21}$ Así es como califica Zygmunt Bauman a Kafka, en Z. BAUMAN: Modernity and Ambivalence, Cambridge, Polity Press, 1991, p. 86.

22 Ibid., p. 91. 
sometan a una crítica feroz. Es el hecho de que la naturaleza de su trabajo y el contenido de éste sean por definición contradictorios con el entorno industrial capitalista, lo que explica que algunos hayan abrazado un credo anticapitalista romántico o marxista. En efecto, el trabajo del escritor es de carácter artesanal $y$, por ende, preindustrial, y el artista se identifica con valores como la unidad entre productor y producto, la autonomía o la realización personal en el trabajo, que no son, precisamente, los valores que rigen en el mundo capitalista. Además, el intelectual y el artista están especializados en la producción de valores espirituales, "cualitativos", extra-comercium, que chocan con los valores cuantitativos que son, como analizara Simmel, los que predominan en la era de la economía monetaria. De ahí que se produzca, como señala Löwy, una antipatía en el sentido alquímico de la palabra, esto es, en el de «falta de afinidad entre dos sustancias», entre dos mundos profundamente heterogéneos: entre el cualitativo y subjetivo del escritor y el cuantitativo y objetivo de la sociedad capitalista $^{23}$. El intelectual y el artista no pueden sino resentir, en suma, que la civilización avance a costa de sus valores más preciados: lo subjetivo, lo personal, lo espiritual y, por ello, algunos llevan su desafección hacia las kafkianas estructuras impersonales de la sociedad moderna y el mercado hasta el extremo de rechazar de plano todo el sistema. Otros se adaptarán a él, pero adoptando una postura crítica y vigilante y sin sentirse del todo nativos.

No sentirse nativo es, en fin, el destino natural del intelectual y el artista por las causas que he señalado y también por las implicaciones psicológicas de su labor. En efecto, la tarea del escritor exige la adopción de una distancia con respecto a la realidad ya que lo que éste recrea en sus obras es fruto de la observación y el análisis de la acción humana. El escritor, así, en cuanto que investigador de la realidad social y del corazón humano tiene necesariamente que distanciarse y, al hacerlo, se está colocando en una postura ambivalente: por un lado, es un miembro activo de la sociedad que analiza y como tal está implicado hasta la médula en ella; por otro, es un observador no participante que se sitúa fuera y adopta la actitud del extranjero que visita un país desconocido y somete a examen lo que ve. Por eso, y concluyendo, puede decirse que el escritor, y en esto se asemeja al sociólogo, es, por su actividad, un extraño parcial del mundo que le rodea y este hiato entre él y el mundo social es lo que motiva que pueda llegar a sentir extrañamiento y desarraigo en mayor medida que otras personas. Además, la naturaleza de su vocación hace que el intelectual y el artista, habitualmente ocupados en discernir el sentido de los actos humanos y de la existencia, estén especialmente necesitados de un universo simbólico total que pueda satisfacer su ansia de significado. No es casual que algunos artistas hayan elaborado un «nomos» casero, de fabricación propia con el que llenar el vacío de una vida social anómica. Las maneras de enfrentar los fenómenos estudiados son, en definitiva, diferentes, pero la centralidad y la relevancia que éstos cobran en sus vidas y obras son un elemento común en todos ellos.

${ }^{23}$ LÖWY, op. cit., p. 21. 


\begin{abstract}
The aim of this paper is to understand why such pathological phenomena as anomy, estrangement and homelessness, which have been tackled by classic and modern sociology, are also the central subject of many great literary works of the 20th century by the likes of Kafka, Sartre, Camus, Roth, T. S. Eliot, Hesse, Lawrence and Musil. The author contends that literary authors, on writing about this problem, are not only mirroring a "sickness» which is generically linked to the condition of man in modern society, but that they are also reflecting their own experience in life. The author attempts to demonstrate that writers, as a social group of intellectuals and artists, are particularly exposed to the syndrome of anomy, estrangement and homelessness for reasons not only linked with their status as stateless and declassed individuals, but also with their task of producing qualitative values which clash with the quantitative logic of the market. This paper, then, is an attempt to contribute simultaneously to a sociology of literary works and the social group of literary creators.
\end{abstract}

